\title{
Theory and Practice of Transboundary Environmental Governance: The Case Study of Tainan Environment Alliance in Taiwan
}

\author{
Po-Yu Lee \\ Department of Social and Public Affairs, University of Taipei, Taipei City, Taiwan \\ Email address: \\ jack3841@gmail.com,jack3841@utaipei.edu.tw
}

\section{To cite this article:}

Po-Yu Lee. Theory and Practice of Transboundary Environmental Governance: The Case Study of Tainan Environment Alliance in Taiwan. Science Innovation. Vol. 4, No. 3, 2016, pp. 127-134. doi: 10.11648/j.si.20160403.12

Received: April 25, 2016; Accepted: June 6, 2016; Published: June 8, 2016

\begin{abstract}
Environmental issues are transboundary in nature and carry the traits of public affairs. Enforcement and consolidation of environmental protection rely on collaborative efforts from different sectors in order to exercise a synergistic effect. In Taiwan, the Tainan Environment Alliance started in 2007 and is a cross-sector collaborative model consisting of the environmental protection authority, the prosecutors' office, the police department, and environmental protection groups that looks up to itself as an effective and successful environmental reporting entity that helps eradicate and prevent crimes against the environment. Methodologically, document analysis and participant observation are adopted in this study in order to get first-hand information and valuable publications on the cross-sector promotion of environmental policies in this particular case. The case study, on the other hand, is done by means of in-depth interviews and phone interviews with members of the Taiwan Environment Alliance, including the environmental protection authority, the prosecutors' office, the police department, and the private sector, over the long term through purposive sampling taking on the qualitative research approach. Results of the study show that besides the collaborative relationship between government agencies and non-governmental organizations, to effectively address environmental protection issues, it also relies on a "dynamic" partnership network and the key lies in how to consolidate environmental issues at the individual cognitive level and to accordingly form a collective force.
\end{abstract}

Keywords: Sustainable Development, Cross-Sector Governance, Environmental Governance, Citizen Participation, Tainan Environment Alliance

\section{跨域性环境治理的理论与实践：以台湾台南环境结盟为例}

\author{
李柏谕 \\ 社会暨公共事务学系，台北市立大学，台北市，台湾 \\ 邮箱 \\ jack3841@gmai1.com, jack3841@utaipei.edu. tw
}

中文摘要: 环境议题兼具跨域性公共事务的特质, 环境保护的执行与落实必须仰赖跨部门协力的运作才能发挥增效效果。 在台湾, 「台南环境结盟」肇始于 2007 年, 由环保机关、检察单位、警察部门与环保团体透过跨部门协力模式, 有效成 功组成环境通报体，打击与防制环境犯罪。本研究在方法应用上将以「文献分析法」、「参与观察法」取得此一个案在 跨部门推动环境政策过程中的第一手信息与宝贵文献, 另一方面, 对于研究个案之处理, 本研究从深度访谈的质性研究 方法出发，以立意抽样的方式，长期针对台南环境结盟参与成员中包含环保、检察、警察、民间等四个部门，进行深度 访谈与电话访问。研究结果发现, 环境保护议题的有效推动, 除了政府部门与民间组织的协力关系之外, 还必须让协力 网络可以「动」起来, 此一关键在于如何将环保议题落实到个人形成认知的基础从而形构集体行动的力量。 
关键词: 永续发展, 跨部门治理, 环境治理, 公民参与, 台南环境结盟

\section{1. 引言}

过去一味追求经济发展与产业成长的台湾社会要转 变为永续型的社会, 绝非仅是政府一己之责, 重大或复 杂的公共议题所相对应的方式，除公私部门的参与外, 更须要结合小区组织与公民团体（林水吉，2009：39）。 长期以来, 台湾政府在经济与产业发展过于重北轻南的 情况之下, 导致南部县市政府不论是对于环保议题的关 注, 或是在地环境污染的解决, 皆出现严重不足的情形, 尤其环境议题兼具跨域性公共事务的特质，环境保护的 执行与落实必须仰赖跨部门协力的运作才能发挥增效 (synergy) 效果。换言之, 环境保护议题的有效推动, 除了政府部门与民间组织的协力关系之外, 还必须让协 力网络可以「动」起来, 此一关键在于如何将环保议题 落实到个人形成认知的基础从而形构集体行动的力量。 对此, 台湾台南市政府于 2007 年透过跨部门协力模式, 首创由环保机关、检察部门、警察单位，以及民间组织 等结合形成一「台南环境结盟」，此一结盟由小区居民 与民间环保团体监督在地环境污染事件，并与台南市政 府环保和警察部门合作，共同成为司法机关的耳目，俾 使检察机关侦办环境污染案件，以建立永续净土、防制 环境犯罪、保护民众生活环境。本研究拟以援引上述的 概念并强化跨部门协力如何「动」起来的论述, 透过台 南环境结盟的推动过程进一步深层思考与论辩, 期盼针 对台南环境结盟的新治理模式本身进行分类、或者在跨 部门协力概念框架上重新探讨其理论内涵的分析, 以期 将相关知识进一步累积成重要的学派或理论主张。就此, 本研究的进行将有三个主要目的与期待: 第一, 本研究 将重新诠释并统合当代政府、市场、社会及地方分权之 治理意涵, 进一步建构以环境议题为中心的跨部门协力 治理模式, 检视公部门与在地民众如何结盟以形塑有效 动员, 共同协力推动环境保护政策。第二, 本研究将研 拟一套策略, 不但能够促使台南环境结盟永续经营, 更 能维系其打击与防制环境犯罪之宗旨, 将是跨域性环境 治理应审慎考虑的方向。最後, 本研究同时希望将跨域 性环境治理机制概念应用在台南环境结盟的推动过程之 中, 试图重新勾勒出中央政府、地方政府、地方组织与 团体，以及在地居民之间的跨部门环境治理之新义。

\section{2. 文献探讨}

\section{1. 跨部门协力治理的动态关系}

自19世纪以来, 公共行政的定位与发展从最早期行政 与政治的二分激辩, 到现今左派国家统治与右派市场决策 的对立论辩, 皆引起了许多在公部门与公共事务管理上的 创新与变革。这些不同的刺激与反省, 在实务发展上出现 了重大转折, 特别是在二十世纪之后, 当政府已非万能且 处于资源与职能有限从而面临政府与市场均产生失灵现
象的窘境之下，昔日僵硬的层级官僚行政模式，逐渐朝向 相对以强调经济、效率、效能之市场为基础，且相对弹性 的新公共管理 (new public management) 模式。然而, 随着全球化效应的发酵，结合各种政治民主化、经济自由 化、社会多元化的影响, 传统人类现实社会生活系络开始 改变, 跨领域性质的公共事务或公共议题的浮现促成了公 共行政学界积极对跨部门治理研究的急迫需求。传统的跨 域治理研究所关怀者, 多半仅聚焦于地理区域的「外溢现 象」或辖区的「越权行为」，近代跨域治理的另一种层面 意涵其实涉及更多元的「治理领域」与为因应治理需求所 需的跨部门治理机制。

值得注意的是, 跨域治理所可能会面临的困境从而 无法达成协力增效之情形, 其原因在于传统「公私协力」

（public-private partnership）的概念界定系指由政 府和公民或「第三部门」共同提供或输送公共财货和服 务的互动协力关系, 此一关系的研究分析背后所隐含的 结果决定论逻辑, 仅能呈现出静态式的协力治理理路; 甚至可能因为经验资料的不足, 将研究自我局限、化约 成静态的治理绩效评估, 从而很可惜地无法展现出跨部 门治理的动态性。对此, 本研究乃援引Lowndes与Sklcher （1998）就多重组织伙伴关系（multi-organizational partnership）所发展出前伙伴合作时期 （pre-partnership collaboration）、伙伴关系建立与 巩固时期 (partnership creation and consolidation)、 伙伴关系服务协力递送时期（partnership program delivery），以及关系终止或延续发展时期等四个不同 的生命周期（life cycle），建构跨部门协力治理的动 态关系（李柏谕2011：52）。如图一所示, 本研究将跨 部门协力治理的动态关系转译成四种不同的关系型态, 在此一背景之下, 动态协力治理的生命周期中, 政府部 门与民间部门一开始为了要促进协力关系, 将会在借着 非正式协商、讨论来形构「前置暖身关系」（如图1之I）。 当政府的公共利益与民间部门的利益逐渐趋合，并进一 步公开讨论并具体化各种制度设计、运作章程、规章、 规范设计时, 透过制度的建立, 两者将进一步进入「巩 固伙伴关系」（如图1之II）。制度的建立确保了协力关 系的发展，同时也紧系着两个部门之间的合作形式与实 质利益, 并就此进入协力传递公共财与公共服务的「协 力治理关系」（如图1之III）。然而, 当两个部门之间 的利害关系随着互动与协力进展而逐渐出现歧见, 两者 将很有可能会步入选择终止跨部门协力实践或持续协力 实践的「治理延续选择阶段」（如图 1 之 IV-A与 IV-B）。 如协力行为者愿意继续合作，则此一跨部门协力治理模 式的动态发展将重新进入稳定的合作阶段; 然而, 如果 双方不愿意继续合作，则将可能会造成契约终止或合作 破局的结果。在此可以初步归纳, 促成每一个阶段转折 的关键，即不同部门之间的利益趋合与分歧的差异。 


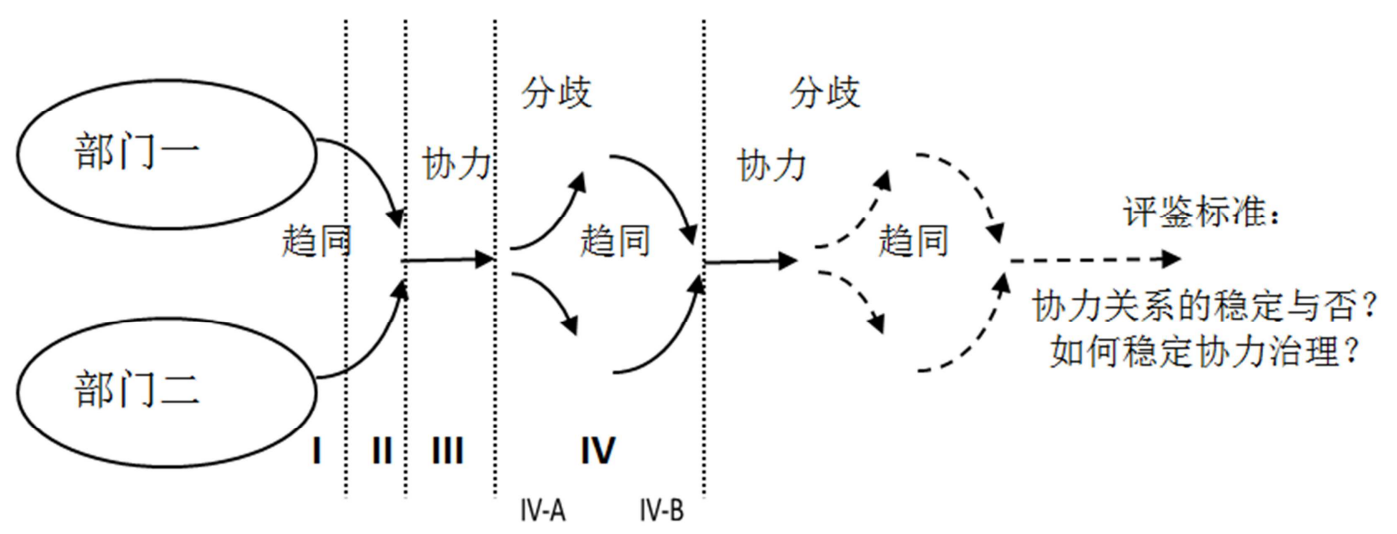

图1 跨部门协力治理的动态关系。

说明:

I. 前置暖身关系：非正式协商与讨论

II. 巩固伙伴关系: 制度建立

III. 协力治理关系：公共财与公共服务的协力传递

IV. 治理延续选择: 选择终止跨部门协力实践 (IV-A) 或持续 (IV-B)

数据源: 李柏谕 (2011: 52)

\section{2. 环境治理的多层面意涵}

「现代环境主义」（modern environmentalism）一 词深受当代社会上及政治上关注的原因, 在于 1962 年 Rache1 Carson在《寂静的春天》（Silent Spring）一书 中指出, 人类科学的发展不能仅仅朝向征服大自然的想法, 而忽略了人类与环境共享共存地球的事实。此一概念开始 刺激人们对于许多环境问题的重视，因而联合国于 1972 年召开第一次「人类环境大会」通过《斯德哥尔摩人类环 境宣言》 ( Stockholm Declaration on the Human Environment）26个原则, 其中宣言的第七点声明当中, 除了指出公民、企业、小区，以及机构的责任外，更强调 国家与地方自治体将于其职责范围内背负最大的负担, 以 推动大规模的环境政策与行动, 此即揭示环境治理 (environmental governance) 概念的意涵（陈建仁、周 柏刘, 2012：126）。循此, 欧洲与英美学者对于环境治 理研究在时间序列的面向上, 可分为二大阶段：第一阶段 以「国家」为主轴因应与管理环境问题, 其他非政府组织、 个人、企业等非国家行为者的角色并未受到太大的重视， 此一时期的研究可称之为「国家强势主导的环境治理时 期」。第二阶段则以「社会」为主轴因应与管理环境问题, 非国家行为者的角色开始带到研究视角的中心, 环境议题 除了国家之外，还存在着民间社会团体等多元复合势力之 影响, 此一时期的研究可称之为「多元整合主导的环境治 理时期」。基于以上二大阶段有关环境议题的研究发展, 让当代环境治理研究产生四种不同但却又相关的研究方 向, 分别为「政府管制」、「市场管制」、「社会管制」, 以及「自我管制」等多层面意涵的研究面向(张文扬, 2014; 李翠萍, 2015）。

在「政府管制」的研究上, 对于环境问题的因应与处 理乃着重在政府所扮演排他性的主导角色，从法令制订、 组织设置、政策执行到绩效评估, 如何推动良善的环境管 制政策以回应不同时期环境危机的挑战，这是最基本的范
围界定研究同时也是公共行政学者最擅长的制度分析, 但 整体上仍缺乏全面与主动的治理特性。如果「政府管制」 的研究是在界定国家如何管制环境的研究内容, 那么「市 场管制」的研究便是在将不同的内容整合到相关的主题上, 也就是环境议题的研究必须超越传统政府组织与法规命 令的范畴。对于「市场管制」的研究, 对于环境问题的因 应与处理则从单纯管制转向到经济诱因, 让污染者主动的 降低对于环境的危害。在「社会管制」的研究上, 此一时 期学者对于政府管制的研究, 开始与治理的概念相互结合, 并提出环境政策的成功需要藉助政府、市场与公民社会三 种治理模式相互链接, 形成彼此协力与合作的网络关系 (Fukuyama, 2013；Lievens，2015)。由上得知, 比较 传统政府管制及市场管制之角色，政府运用管制工具以因 应环境问题产生了另一种新的选项：「交互式的治理」, 强调公部门、私部门与第三部门伙伴关系的合作，各部门 不论达成的协议有多少，都要允诺共同合作，以解决特定 的环境难题（Glasbergen, 1998:1）。最后，在「自我管 制」的研究上, 研究主要聚焦在公民参与式 (citizen participation）的环境政策之实践, 也意味着民主价值 的展现以及公民权利的行使与争取（Morse，2006）。公 民参与指民众基于对公共事务的认知与情感, 透过与政府 间的公开对话, 参与公共决策所涉及的问题, 以此进一步 影响公共事务的过程。公民参与在公共行政的研究领域之 中, 一直是个重要概念, 尤其连结地方治理（1ocal governance)、小区营造（community development）及 审议式民主（deliberative democracy）等议题时，皆扮 演着公民社会实践的关键因素 (杜文苓、施佳良、蔡宛儒, 2014）。过去，整个环境政策的制定与执行一直缺少公民 参与的机会及管道, 不仅造成公私部门间在认知上存在着 许多落差, 而且还直接或间接形成彼此间的不信任感, 政 策执行的最终结果皆告失败。其实环境政策的作成可以使 用「参与」、「协商」、「对话」等方式, 强调「与民规 划、由民规划」（planning with people, planning by 
people) 的由下而上之参与式方式(李永展, 2000: 54-55), 不但可提升有关正式及非正式间强而有力的理性及建构 正义的想法, 更可以达到使环境决策更趋于公义的使命, 以强化政策的正当性。

\section{3. 以环境议题为中心的跨部门协力治理模式}

以环境议题中的新治理逻辑, 这个新的逻辑主要可以 从跨部门协力机制与跨部门协力特色两个层面来看, 如图 2所示, 本研究认为以公部门、私部门与第三部门伙伴关 系为主的环境治理机制上将具有三种形式:

1. I+I协力: 举公部门的例子来说, 单单一个政府部 门在面对环境管理的过程中往往显得势力单薄, 一般咸认为中央层级的公部门（中央政府）是因 应生态破坏与环境污染最主要的行为者, 但随着 民主治理概念的引入，地方层级的公部门（地方 政府）加入环境管理过程所建立的公部门群的纵 向合作与协调, 把中央与地方在环境管制与配搭
的规范、责任与工作提升为公部门之间的有效协 力关系（图2之A的 I+I协力）。

2. I+II协力: 为了追求更健全永续发展机制, 环境 治理不再只是中央政府的责任，政府会将触角展 延到其他的合作部门中, 对私部门来说, 不同企 业主动或被动地参与环境管理的过程, 让环境管 理有了更多的资源, 无论在财政经费上、管理经 验上、人力资源上都有了更充裕的支持, 而这种 公私协力关系的建立（图2之B的I+II协力）让环 境管理的执行更加顺利。

3. I+III协力: 政府与非政府组织或非营利组织等第 三部门的合作, 最容易出现在环境治理过程中 (图 2 之C 的I+III协力），因为这种协力方式显得最为 弹性, 各种第三部门的志工往往在政府还没发现 生态破坏与环境污染之前便随着地方网络的经营 而取得了监控环境犯罪的管道。他们不但掌握了 监控环境犯罪的弹性, 同时也是在监控环境犯罪 进行有效制止与防范工作为期最长久的团队。

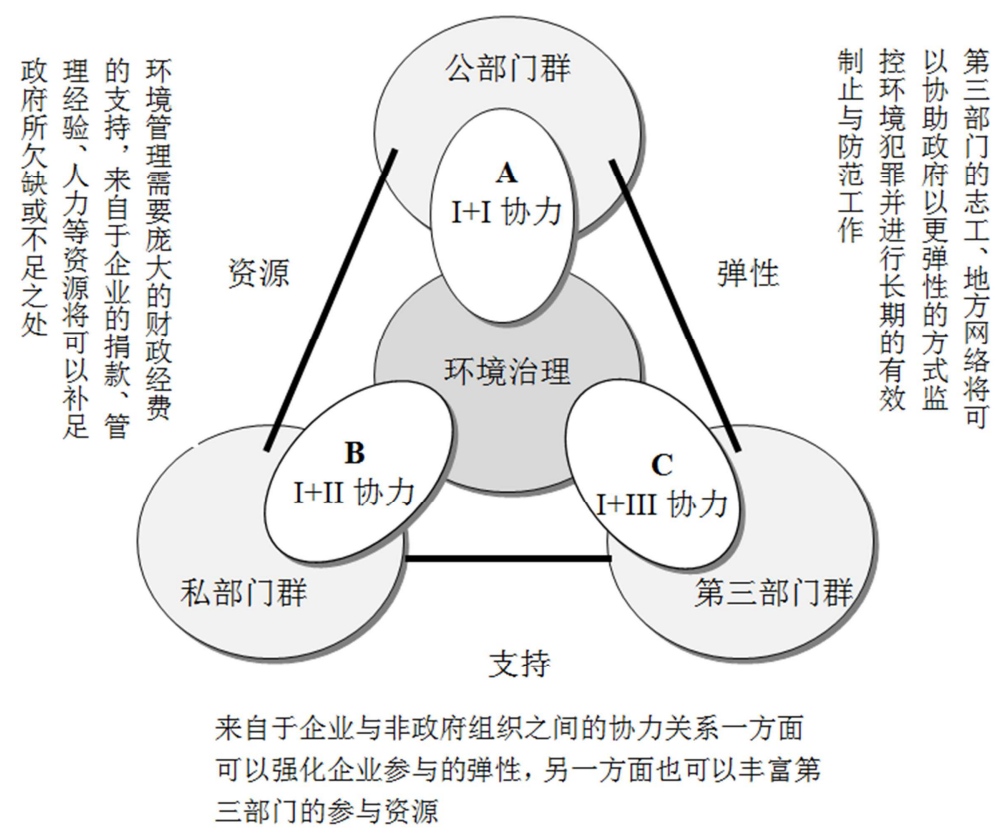

数据源: 本研究自绘

图2 以环境议题为中心的跨部门治理。

相比之下, 从环境管理的议题之中看这些跨部门协力 关系最主要的特色, 在公部门与私部门的协力关系中最重 要的特色就是引入「资源」, 特别在环境管理上需监控环 境犯罪的有效制止与防范工作都需要庞大的财政经费的 支持，来自于企业的捐款、管理经验、人力等资源将可补 足政府欠缺之处。而公部门与第三部门的协力关系最重要 的特色就是争取「弹性」, 第三部门的志工、地方网络将 可协助政府以更弹性的方式进入监控环境犯罪并进行长 期的制止与防范工作。最后, 私部门与第三部门的协力关 系最重要的特色就是争取「支持」。如来自于企业与非政 府组织之间的协力关系一方面可以强化企业参与的弹性, 另一方面也可以丰富第三部门的参与资源, 有了这些整合 性的社会资源, 将可以协助政府因应生态破坏与环境污染
的落实。所以, 整体说来, 在环境治理过程里, 政府不只 是要规划环境管制的标准作业程序, 提供制度上的权责划 分并追求环境管理的善治才是真正的关键，在这个前提下， 公部门群、私部门群、第三部门群之间所构成的铁三角关 系, 则缺一不可。

\section{3. 研究方法}

为了要处理理论层面的研究问题, 本研究在方法应用 上将以「文献分析法」、「参与观察法」取得此一个案在 跨部门推动环境政策过程中的第一手信息与宝贵文献。另 一方面, 对于研究个案之处理, 本研究从深度访谈的质性 研究方法出发, 以立意抽样 (purposive sampling) 的方 
式, 长期针对台南环境结盟参与成员中包含环保、检察、 警察、民间等四个部门, 进行深度访谈与电话访问。透过 交叉运用非结构性的「访谈纲要」（interview guide） 与「标准化开放访谈」 ( standardized open-end interview），进行第一手的资料搜集与整理工作，期以 台南环境结盟为个案进一步说明参与结盟的部门成员在
协力互动过程中, 如何有效改善台南地区环境污染及犯罪 问题, 并从中了解本文所欲研究命题的内在观点, 以创造 环境保护、经济发展及公平正义三赢局面。

\section{4. 研究结果}

跨域性环境治理架构

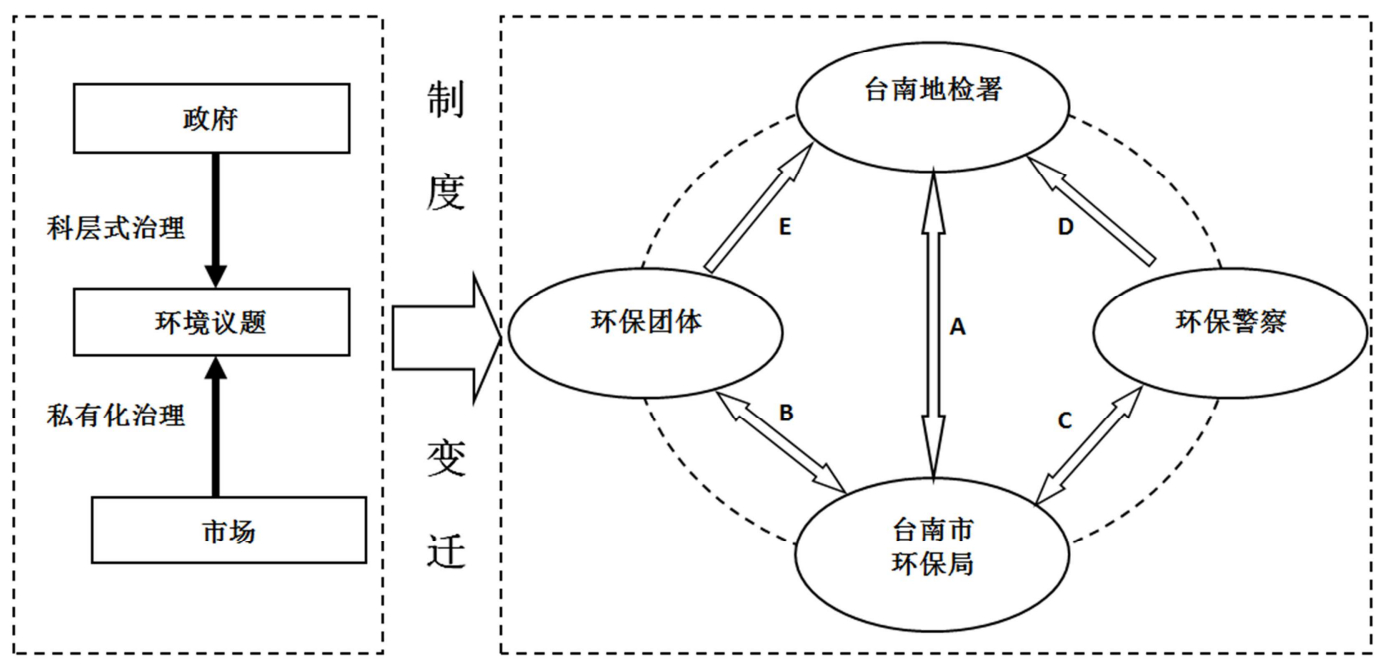

图3 台湾台南环境结盟的治理架构分析。

\section{1. 推动台南环境结盟的治理架构分析}

传统上, 台湾政府对于环境问题的因应与处理方式多 半以科层式由上而下的政策工具加以解决, 也就是透过从 法令制订、组织设置、政策执行到绩效评估等一连串的政 府管制运作, 响应不同时期环境问题的挑战。然而, 这样 的环境管制政策整体上仍缺乏全面与主动的治理特性, 从 而出现市场管制的概念, 也就是将环境问题的因应与处理 转向到经济诱因的私有化治理, 让污染者主动降低对于环 境的危害。值得注意的是, 环境议题为跨领域性质的公共 事务或公共议题, 缺乏公民自主参与的原素将使台湾环境 管理议题陷入困境。台湾台南环境结盟肇始于 2007 年元月, 主要原由乃因台南地检署鉴于国土犯罪侦查长期流于零 星分散, 故邀集大台南地区的其他相关公权力单位、环保 团体及学术单位等, 共同举办环境犯罪防治座谈会, 以找 出有效对策打击环境犯罪。 ${ }^{1}$ 如图3所示, 台南环境结盟 是由环保机关、检察单位、警察部门与环保团体共同签约 结盟, 透过跨部门合作机制组成环境通报体系, 打击环境 污染, 防制环境犯罪, 并解决环境公共问题。从「传统环 境议题的处理」到「跨域性环境治理架构」的历史发展轨 迹来看台南环境结盟的治理架构, 此一制度变迁在路径依 赖的动态过程中产生「自我增强」与「正向回馈」的结果。

整体而言, 作为跨部门协力机制的台南环境结盟成员, 每个部门都扮演着不同角色, 首先, 「台南市环保局」拥 有在地主管机关之合法权力, 对于地域污染问题较为熟悉,

1 http://en. eja. org. tw/19/post/2012/10/1.htm1 (Environmental Jurists Association网站, 2013/12/10汶览)
在结盟运作中扮演受理环保团体、台南地检署与环保警察 所通报的污染情形并负责处理与回复处理情形（图3之A、 B、C）。「环保警察」拥有在辖区调查并搜证环境犯罪之 合法权力, 在结盟运作中扮演执行者的角色, 除了协助台 南市环保局稽查秩序维护, 并排除不法阻力之外, 还要提 供台南地检署办理环境犯罪刑事案件之事证 (图3之C、D)。 「环保团体」属于民间团体组织拥有强烈环保意识与公民 参与, 诸如台南小区大学、台南市环境保护联盟、荒野保 护协会台南分会、台湾湿地保护联盟等十余个团体在台南 地区相当活跃, 在结盟运作中扮演环境巡守及台南市环保 局通报环境污染案件并协助台南地检署搜证环境犯罪的 重要角色（图3之B、E）。「台南地检署」拥有刑事侦查 犯罪之权力, 因属中立性的司法角色一职而与地方特权之 瓜葛较少, 可协助行政部门稽查时排除地方业者向其关说 与施压之外力不当干预（图3之A）。由以上得知, 随着近 代公民参与理论和赋权自主管理概念的兴起（Wi jayanti and Suryani, 2015; Mattessich, 2009; Chilvers, 2008; Green and Haines, 2008; 杜文苓, 2010; 江大树、张力 亚, 2008），台南环境结盟的形成与运作过程中，台南地 检署不仅扮演着重要催生者, 同时采取以民为主强化由下 而上的地方参与之创意思考, 将参与结盟的各部门作一资 源整合及业务分工合作，为环境保护政策领域创造新思维 的跨部门合作方式。

2 台南地检署则采取以民为主、创意思考及资源结合的办案思维, 以优 先办理民众关注案件, 整合社会资源并形塑检察机关公益角色及扩大民 众参与以期在环境保护领域创造新思维的合作方式 (曾昭恺, 2009: 12)。 


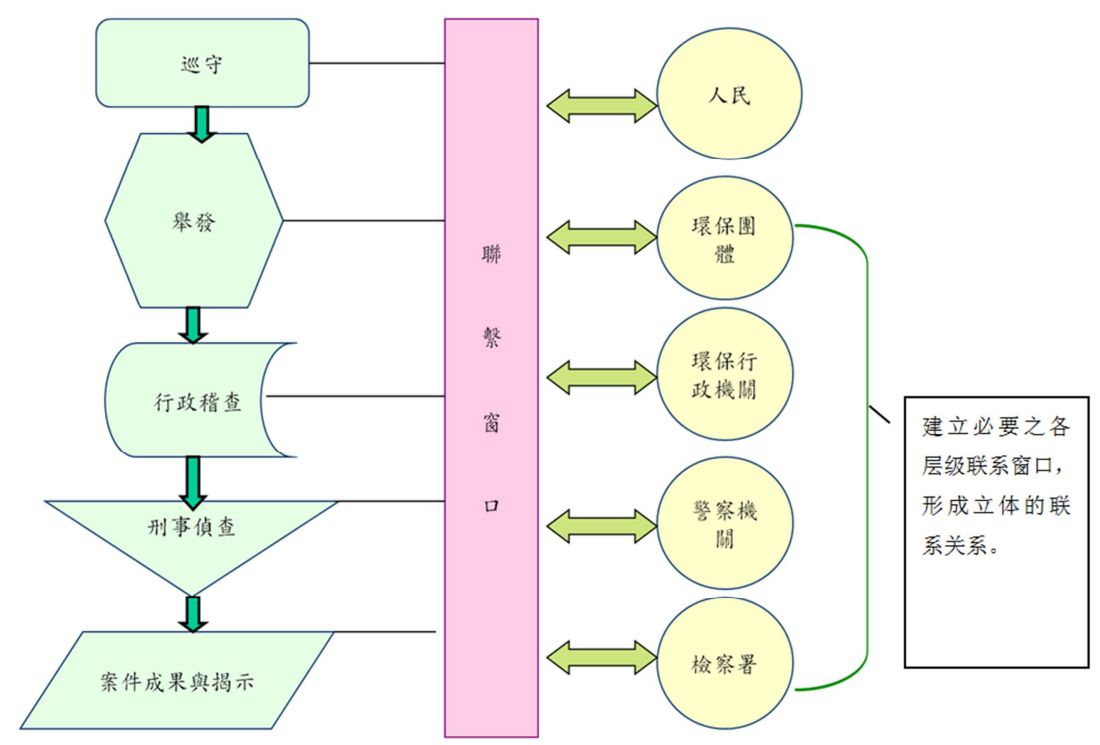

数据源: 台南地检署（2007）

图4 台湾台南环境结盟的一般稽查模式与联系窗口。

如以上图4所示, 台南环境结盟的一般稽查模式分为 五大阶段：（1）巡守：日常对活动环境之观察;（2）举 发: 对于生活环境污染举发之管道及辨识搜证; (3) 行 政稽查: 属于公权力对于生活环境污染之辨识搜证; (4) 刑事侦查: 属于司法机关对于对于生活环境污染之搜证侦 办; （5）案件成果与揭示：建置地区污染信息网站，揭 示查缉成果，促进全民监督（台南市环保局, 2012）。如 表1所示, 在这五大环境稽查阶段的窗口联系方面, 台南 环境结盟的「台南市环保局」、「环保警察」、「环保团
体」及「台南地检署」等各部门各自扮演互补的功能性角 色, 透过跨部门合作机制有效成功组成环境通报体系, 打 击与防制环境犯罪。整体来说，台南环境结盟以公民参与 为地方治理中心，强调中央、地方主管机关「由上而下」 辅助并赋权让民间团体与小区组织「由下而上」共同参与 打击不法环境犯罪以捍卫环境正义，其建构一个「跨域性 环境治理架构」是一种新型态跨领域合作模式, 至今仍稳 定运作，被外界视为是成功的个案。

表1 结盟稽查阶段与任务。

\begin{tabular}{|c|c|c|c|c|c|}
\hline 参与者 & 人民 & 环保团体 & 行政环保机关 & 警察机关 & 检察署 \\
\hline 稽查程序 & & & & & \\
\hline 巡守 & $\begin{array}{l}\text { 日常对活动 } \\
\text { 环境之观 } \\
\text { 察。 }\end{array}$ & $\begin{array}{l}\text { 1. 专职及志工巡守。 } \\
\text { 2. 伙伴关系团体、小区组 } \\
\text { 织志工巡守。 }\end{array}$ & $\begin{array}{l}\text { 1. 例行定时、不定时巡守。 } \\
\text { 2. 专案巡守。 } \\
\text { 3. 参与联合查缉、监控。 } \\
\text { 4. 发动河川巡守队及体巡守。 }\end{array}$ & $\begin{array}{l}\text { 1. 环保䇾祭队: 台南地区 } \\
\text { 监控案件之查案人力。 } \\
\text { 2. 县市警察局: 一般警勤 } \\
\text { 区巡逻时, 同时注意环境 } \\
\text { 污染公害。 }\end{array}$ & $\begin{array}{l}\text { 1. 巡讨足期安排㵖流污 } \\
\text { 染地区巡查。 } \\
\text { 2. 不定时地以预防犯罪 } \\
\text { 之陪同角色参与环保局 } \\
\text { 之行政巡查。 }\end{array}$ \\
\hline 举发 & $\begin{array}{l}\text { 1. 对生活环 } \\
\text { 境污染之举 } \\
\text { 发 } \\
\text { 2. 知悉检举 } \\
\text { 管道。 } \\
\text { 3. 污染情形 } \\
\text { 之辨识与紧 } \\
\text { 急搜证。 }\end{array}$ & $\begin{array}{l}\text { 1. 巡守发现污染之及时 } \\
\text { 通报及污染来源之及时 } \\
\text { 追踪。 } \\
\text { 2. 民众检举之辅助性通 } \\
\text { 报系统。 } \\
\text { 3. 环境污染点之建议。 } \\
\text { 4. 台南地区污染网站上 } \\
\text { 检举案件整理 }\end{array}$ & $\begin{array}{l}\text { 1. 公开公害检举窗口。 } \\
\text { 2. } 24 \text { 小时值勤处理。 } \\
\text { 3. 检举讯息之揭示。 } \\
\text { 4. 公布重大污染讯息, 结合相关团体 } \\
\text { 宣示查缉决心。 }\end{array}$ & $\begin{array}{l}\text { 1. 环保警察队: 向督察大 } \\
\text { 队或辖区环保局通报。 } \\
\text { 2. 县市警察局: 辖区环保 } \\
\text { 局通报。 }\end{array}$ & $\begin{array}{l}\text { 1. 协助通报。 } \\
\text { 2. 刑案发现重点污染对 } \\
\text { 象之举发。 }\end{array}$ \\
\hline 行政稽查 & & & $\begin{array}{l}\text { 1. 查证污染情形。 } \\
\text { 2. 行使行政检查权。 } \\
\text { 3. 采样鉴定 } \\
\text { 4. 告发 (限县市环保局)。 } \\
\text { 5. 机具设备之扣留、没入、禁止使用。 }\end{array}$ & $\begin{array}{l}\text { 1. 协助环保机关稽查秩序 } \\
\text { 维护排除不法阻力。 } \\
\text { 2. 附带刑事案件搜证。 } \\
\text { 3. 奖励警力配合环境行政 } \\
\text { 稽查。 }\end{array}$ & $\begin{array}{l}\text { 1. 协调环保局与警局, 环 } \\
\text { 保团体与环保局之关系。 } \\
\text { 2. 协助排除外力不当干 } \\
\text { 预。 }\end{array}$ \\
\hline 刑事侦查 & & $\begin{array}{l}\text { 1. 协助搜证。2. 担任目击 } \\
\text { 证人。 } \\
\text { 3. 专家证人证述。 }\end{array}$ & $\begin{array}{l}\text { 1. 涉嫌刑事案件之告发。 } \\
\text { 2. 协助搜证、采样鉴定、环保申报登 } \\
\text { 记等资料提供、专业咨询。 } \\
\text { 3. 专家证人证述。 }\end{array}$ & $\begin{array}{l}\text { 1. 辖区环保局、督察大队 } \\
\text { 案件之侦查、移送 (限县 } \\
\text { 市警察局)。 } \\
\text { 2. 检察官指挥案件之侦 } \\
\text { 查、移送。 }\end{array}$ & $\begin{array}{l}\text { 1. 因巡守、行政检查所发 } \\
\text { 现刑事案件之及时入。 } \\
\text { 2. 后续之指挥、搜证、起 } \\
\text { 诉。 } \\
\text { 3. 机具、设备之扣押, 不 } \\
\text { 法所得之查扣。 }\end{array}$ \\
\hline
\end{tabular}




\begin{tabular}{|c|c|c|c|}
\hline 稽查程序 人民 & 环保团体 & 行政环保机关 & 检察署 \\
\hline $\begin{array}{l}\text { 案件成果与 } \\
\text { 揭示 }\end{array}$ & $\begin{array}{l}\text { 1. 重点巡守。 } \\
\text { 2. 建置地区污染信息网 } \\
\text { 站, 揭示查缉成果, 促进 } \\
\text { 全民监督。 } \\
\text { 3. 解决问题方案之建议。 }\end{array}$ & $\begin{array}{l}\text { 1重点巡查, 再犯之告发与移送刑案。 } \\
\text { 2. 防止工更换人头之作为。 } \\
\text { 3. 提供告发案件数据, 以供全民监 } \\
\text { 督。 } \\
\text { 4. 根治问题方案之提出。 } \\
\text { 5. 推荐重大污染案件之检举人以领 } \\
\text { 取环保奖金。 }\end{array}$ & $\begin{array}{l}\text { 1. 提供侦审数据以供全 } \\
\text { 民监督。 } \\
\text { 2. 协助环保机关从根本 } \\
\text { 解决地区污染问题。 }\end{array}$ \\
\hline
\end{tabular}

数据源: 台南地检署, 2007

\section{2. 台南环境结盟的治理成功要素}

\section{2. 1. 领导者的功能发挥}

台南环境结盟是个跨中央与地方及公私部门的组织, 在异业结盟的组织下, 由台南地检署担任领导者角色, 有 效化解外力对环境稽查的不当干预。因此, 若无地检署的 带领，行政机关、警察机关或许无法有效的发挥部门功能 而协力的运作亦不至于如此顺利。

\subsection{2. 协力成员的实质参与及意见落实}

多数环保团体或小区组织对于政府法规更新或环保 讯息的取得是略为被动、缓慢，公部门可透过管道如正式 会议或者私下沟通讨论的方式，提供平台予参与者表达其 观点, 并在可行范围内做为决策制订的方向与讨论基础以 强化政策结果的正当性，也可以维持结盟成员间的热度。

\subsection{3. 面对面对话}

政府制定政策方向或法规命令, 如果能在任何结果产 出前, 透过双向沟通 (two-ways communication) 的方式, 让利害关系人可以经由如参加正式的会议或非正式的沟 通管道, 可协助协力成员在更快速与便利的情形下, 就环 保犯罪案件执行面向做临时性的讨论。

\subsection{4. 互信的网络建立}

环保犯罪牵涉的层面广泛，唯有透过信任的合作机制 进行跨部门的协力支持才能竟功, 例如在环境结盟运作中, 行政机关基于信任授予已接受完整训练的环保团体采样 权并相信检察机关面对外在压力的抗衡能力及警察单位 可以适时的维护秩序和保障人身安全。

\subsection{5. 互动过程中的承诺}

参与者在协力场域中必须履行责任义务、尊重不同参 与者所提出的意见、想法、遵守共同协商后的共识及协力 成果, 并确信协力过程的运作是完善的。于协力运作中, 为求更有效的运作, 各部门或许会微幅的牺牲或承担额外 事务, 但多数情况皆涵括在公部门执行公务范围内, 并无 造成过多负荷。

\section{2. 6. 资源共享机制的建立}

环境结盟的宗旨，乃希望透过环保、检察、警察跟民 间组织的合作，让司法、行政及民间团体等环节能互补不 足, 并产生良性互动之正向循环。事实上, 环保团体与行 政机关之间存有异议乃思维不同所致，但可藉由互动连系、
沟通取得对问题的共识, 或由媒体力量揭露影响政府的重 视或改善。

\subsection{7. 协力正面效益的产出}

环境结盟的运作方式在策略规划、计划执行与结果评 估阶段皆有正向的即刻成果产出, 数个正向即刻结果形成 小赢模式 (small wins)。对台南环境结盟而言, 除了希望 运用公私协力的跨部门力量, 解决环境污染犯罪问题外, 更期望透过各阶段的小赢模式反馈检视流程是否有需要 修正调整的部分, 将可做为后续协力运作的依循。

\section{5. 結語}

台湾台南环境结盟自 2007 年透过跨部门力量打击不 法环境犯罪以捍卫环境正义, 历经多年努力, 无论在水污 染、事业废弃物或固定污染源的稽查方面都有相当成效, 尤其一些环保业者为了规避取缔而将污染转移至邻近县 市，让此一环境结盟体系朝向跨县市合作机制建立的发展 趋势, 以对环境的伤害并降至最低。另一方面, 公民参与 为当今治理重要的一环, 环境结盟强化与小区居民的连结 也可以在潜移默化中影响更多人对于环保议题的关注, 无 形中也进行了环境教育的工作。最后，公私部门间合作推 动环境保护工作其互动方式与权力的运作该如何调适与 分配值得后续更进一步深入探究。

\section{参考文献}

[1] Fukuyama, Francis. (2013). “What Is Governance?” Governance: An International Journal of Policy, Administration, and Institutions, 26(3), 347-368.

[2] Glasbergen, Pieter. (1998). "The question of environmental governance." in Glasbergen ed. Co-oprative environmental governance. Kluwer Academic Publishers: Netherlands.

[3] Green, G. P. , \& A. Haines. (2008). Asset building and community development. Los Angeles: SAGE Publications.

[4] Lievens, Matthias. (2015). "From Government to Governance: A Symbolic Mutation and Its Repercussions for Democracy." Political Studies, 63(S1), 2-17. 
[5] Lofland, J. and Lofland, L. H. (1984). Analyzing social settings. Belmont, CA: Wadsworth.

[6] Lowndes, Vivien and Chris Skelcher. (1998). "The Dynamics of Multi-Organizational Partnerships: An Analysis of Changing Modes of Governance." Public Administration, 76(Summer), 313-333.

[7] Mattessich, P. W. (2009). "Social capital and community building. ” In. R. Phillips \& R. H. Pittman eds. An introduction to community development. London: Routledge.

[8] Morse, R. S. (2006). "Prophet of participation: Mary parker follett and public participation in public administration." Administrative Theory \& Praxis, $28(1), \quad 1-32$.

[9] Wi jayanti, D. R. , \& Suryani, S. (2015). “Waste Bank as Community-based Environmental Governance: A Lesson Learned from Surabaya. ” Procedia-Social and Behavioral Sciences, 184, 171-179.

[10] 江大树、张力亚。（2008）。小区营造中组织信任的机制建 构: 以桃米生态村为例。东吴政治学报，26(1)，87-142。

[11] 李永展。(1994)。环境态度与环保行为-理论与实证。台北: 胡氏图书出版社。

[12] 李柏谕。（2011）。跨部门治理的理论与实践：以莲潭国际 文教会馆的委外经验为例。公共行政学报, 40, 41-76。
[13］李翠萍。(2015)。环境污染对邻近区域的影响分析--以台 中市污染场址周边地价为例。中国行政评论, 21(4), 页 17-47。

[14］杜文苓。(2010)。环评决策中公民参与的省思：以中科三 期开发争议为例。公共行政学报, 35, 29-60。

[15］杜文苓、施佳良、蔡宛儒。(2014)。传统农业县的石化课 题: 检视六轻环境争议与治理困境。台湾土地研究, 17 (1), 页59-90。

[16] 林水吉。(2009)。跨域治理一理论与个案研析。台北: 五 南。

[17］张文扬。（2014）。民主与环境治理--一个遴选集团理论的 解释。台湾民主季刊, 11(3), 页1-39。

[18］陈建仁、周柏站。(2012)。都市内分权与环境治理机制以台中市大雪山小区为例。台湾民主季刊, 9(2), 页 125-165。

[19］曾昭恺。（2009）。环境结盟之过去、现在与未来。收录于 环境污染与环境结盟研讨会论文及暨成果报告书。台南县: 环境保护局。

[20］台南市环保局。(2011)。大台南环检警结盟第二次座谈会。 台南: 台南市环保局。

[21]台南市环保局。(2012)。大台南环检警结盟第三次座谈会。 台南: 台南市环保局。

[22］台南市环保局。(2013)。大台南环检警结盟第四次座谈会。 台南: 台南市环保局。

[23］台南地检署。(2007)。座谈会简报（结论版）。台南：台南 地方法院检察署。 